\title{
Chemical Profiles and Pharmacological Properties with in Silico Studies on Elatostema papillosum Wedd
}

\author{
Md. Zia Uddin ${ }^{1,2}$, Arkajyoti Paul ${ }^{1}$ (D) Ahmed Rakib ${ }^{3}{ }^{(D}$, Saad Ahmed Sami $^{3}$ (D) Shafi Mahmud ${ }^{4}$, Md. Sohel Rana ${ }^{2}$, \\ Shahadat Hossain ${ }^{5}$, Abu Montakim Tareq ${ }^{6} \mathbb{D}$, Mycal Dutta ${ }^{1,2} \mathbb{D}$, Talha Bin Emran ${ }^{1, *(D)}$ \\ and Jesus Simal-Gandara ${ }^{7, *}$ (D)
}

check for

updates

Citation: Uddin, M.Z.; Paul, A.;

Rakib, A.; Sami, S.A.; Mahmud, S.;

Rana, M.S.; Hossain, S.; Tareq, A.M.;

Dutta, M.; Emran, T.B.; et al.

Chemical Profiles and

Pharmacological Properties with in

Silico Studies on Elatostema papillosum

Wedd. Molecules 2021, 26, 809.

https://doi.org/10.3390/

molecules26040809

Academic Editor: Luisella Verotta

Received: 12 January 2021

Accepted: 1 February 2021

Published: 4 February 2021

Publisher's Note: MDPI stays neutral with regard to jurisdictional claims in published maps and institutional affiliations.

Copyright: (C) 2021 by the authors Licensee MDPI, Basel, Switzerland. This article is an open access article distributed under the terms and conditions of the Creative Commons Attribution (CC BY) license (https:/ / creativecommons.org/licenses/by/ $4.0 /)$.
1 Department of Pharmacy, BGC Trust University Bangladesh, Chittagong 4381, Bangladesh; zia@bgctub.ac.bd (M.Z.U.); arka.bgctub@gmail.com (A.P.); mycal@bgctub.ac.bd (M.D.)

2 Department of Pharmacy, Jahangirnagar University, Savar, Dhaka 1342, Bangladesh; sohelrana.ju@gmail.com

3 Department of Pharmacy, Faculty of Biological Sciences, University of Chittagong, Chittagong 4331, Bangladesh; rakib.pharmacy.cu@gmail.com (A.R.); s.a.sami18pharm@gmail.com (S.A.S.)

4 Microbiology Laboratory, Bioinformatics Division, Department of Genetic Engineering and Biotechnology, University of Rajshahi, Rajshahi 6205, Bangladesh; shafimahmudfz@gmail.com

5 Atomic Energy Centre, East Nasirabad, Chittagong 4209, Bangladesh; sahedmc@gmail.com

6 Department of Pharmacy, International Islamic University Chittagong, Chittagong 4318, Bangladesh; montakim0.abu@gmail.com

7 Nutrition and Bromatology Group, Department of Analytical and Food Chemistry, Faculty of Food Science and Technology, University of Vigo-Ourense Campus, E32004 Ourense, Spain

* Correspondence: talhabmb@bgctub.ac.bd (T.B.E.); jsimal@uvigo.es (J.S.-G.); Tel.: +880-181-994-2214 (T.B.E.); +34-988-387000 (J.S.-G.)

Abstract: The current study attempted, for the first time, to qualitatively and quantitatively determine the phytochemical components of Elatostema papillosum methanol extract and their biological activities. The present study represents an effort to correlate our previously reported biological activities with a computational study, including molecular docking, and ADME/T (absorption, distribution, metabolism, and excretion/toxicity) analyses, to identify the phytochemicals that are potentially responsible for the antioxidant, antidepressant, anxiolytic, analgesic, and anti-inflammatory activities of this plant. In the gas chromatography-mass spectroscopy analysis, a total of 24 compounds were identified, seven of which were documented as being bioactive based on their binding affinities. These seven were subjected to molecular docking studies that were correlated with the pharmacological outcomes. Additionally, the ADME/T properties of these compounds were evaluated to determine their drug-like properties and toxicity levels. The seven selected, isolated compounds displayed favorable binding affinities to potassium channels, human serotonin receptor, cyclooxygenase-1 (COX1), COX-2, nuclear factor (NF)- $\mathrm{B}$, and human peroxiredoxin 5 receptor proteins. Phytol acetate, and terpene compounds identified in E. papillosum displayed strong predictive binding affinities towards the human serotonin receptor. Furthermore, 3-trifluoroacetoxypentadecane showed a significant binding affinity for the KcsA potassium channel. Eicosanal showed the highest predicted binding affinity towards the human peroxiredoxin 5 receptor. All of these findings support the observed in vivo antidepressant and anxiolytic effects and the in vitro antioxidant effects observed for this extract. The identified compounds from E. papillosum showed the lowest binding affinities towards COX-1, COX-2, and NF- $\mathrm{KB}$ receptors, which indicated the inconsequential impacts of this extract against the activities of these three proteins. Overall, E. papillosum appears to be bioactive and could represent a potential source for the development of alternative medicines; however, further analytical experiments remain necessary.

Keywords: Elatostema papillosum; phytochemicals; medicinal plants; traditional medicine; molecular docking 


\section{Introduction}

Depression is the most widespread mental disorder and is recognized to present with heterogenous symptoms associated with a variety of psychological and biological factors [1]. Despite the availability of well-known antidepressant drugs [2], basic neuroscience suggests that the discovery of novel mechanisms may lead to the development of more effective pharmacotherapies, which has resulted in the exploration of new molecules with rapid-onset antidepressant and anxiolytic effects while being associated with fewer side effects than current medications [3]. The International Association for the Study of Pain defines pain as an unpleasant sensory and emotional experience, which is typically associated with actual or potential tissue damage [4]. Inflammation is the multifarious biological reaction of the vascular tissue in response to injurious stimuli, including the presence of pathogens, damaged cells, or irritants. Inflammation can result in the local accumulation of plasmatic exudations and blood cells, resulting in the development of inflammatory diseases, such as various types of arthritis, including rheumatoid and gouty arthritis and shoulder tendinitis [5]. Despite the development of recent therapies, the medical community continues to seek more potent and useful analgesics [6], which has encouraged interest in secondary metabolites derived from plants as potential sources of new drug molecules that are clinically effective. Oxidation, which is initiated by reactive free radical species, is another compelling issue. Free radicals can cause various types of disorders in humans, including central nervous system (CNS) injuries, ischemia, atherosclerosis, reperfusion, cancer, gastritis, AIDS, and arthritis [7]. Recently, plant-derived secondary metabolites have been increasingly analyzed as part of the search for novel free radical scavengers [8]. To reduce the occurrence of free-radical-induced diseases, however, additional information regarding the antioxidant effects of plant-derived substances must be elucidated. Because of these existing limitations, attempts are in progress to explore better replacement of these drugs. In this context, indigenous information can contribute to the development of new drugs from medicinal plants [9-13].

We selected the plant E. papillosum, which belongs to the Urticaceae family, for our study. Several Elatostema species are located in the regions of Africa, Asia, Australia, and Oceania. E. papillosum is found throughout China, Bhutan, India, and Bangladesh [12]. This species is typically found in the hilly areas of the Chittagong district in Bangladesh [12]. E. papillosum was selected because most of the pharmacological activities associated with this plant, including the isolation of bioactive phytochemicals have not been well-investigated. Previous reports state that crushed E. papillosum plants are used in traditional medicine for hysteria and abdominal pain treatment. To our knowledge, there have been no reported pharmacological outcomes of E. papillosum except the applications for hysteria treatment by local practitioners [12]. In the present study, we aimed to explore the bioactive phytochemicals found in E. papillosum using gas chromatography-mass spectrometry (GC-MS). Systemic, guided, separation and identification techniques are essential for revealing the potential bioactive and toxic phytochemicals found in plants, as plants contain a variety of phytochemicals [13]. GC-MS, together with the use of proper detection techniques, represents a vital means for the separation and identification of phytochemicals [14]. GC-MS can be easily used to analyze small, volatile, and thermostable components [15-18].

Previously, our group investigated the in vivo antidepressant, analgesic, and antiinflammatory activities and the in vitro antioxidant and antibacterial activities of various fractions of crude methanol E. papillosum extracts [19]. The crude methanol extract and its chloroform soluble (CS) fraction showed significant antidepressant, analgesic, and antiinflammatory activities. The methanol extract and its CS fraction also showed significant DPPH free-radical-scavenging activity, and the methanol extract showed antimicrobial activity. Similarly, the petroleum ether soluble (PES) fraction showed significant antidepressant and anti-inflammatory activities [19].

Because the extracts of this plant showed various beneficial effects, we aimed to correlate these previously reported biological activities, especially the antidepressant, anxiolytic, and antioxidant activities, with the results of a computationally-aided molecular docking 
study to provide some evidence for the traditional and novel therapeutic applications of E. papillosum.

\section{Results}

\subsection{GC-MS Analysis}

A total of 24 compounds were isolated from E. papillosum using GC-MS spectroscopy, which are listed in Figure 1 and Table 1, along with their chemical compositions. The total ionic chromatogram (TIC) is shown in Figure 2. Seven compounds were selected for molecular docking analyses because the specific biological activities of interest have not yet been established for these compounds.<smiles>CCCCCCCCCCCCC(C)(CC)OC(=O)C(F)(F)F</smiles>

(A)<smiles>CCCCCCCCCCCCCCCCCCCCCC(N)=O</smiles>

(B)<smiles>CCCCCCCCCCCCCCCCCCCC=O</smiles>

(C)<smiles>CCCCC/C=C\C/C=C\CCCCCCCC(=O)O</smiles>

(D)<smiles>CC/C=C\C/C=C\C/C=C\CCCCCCCC(=O)OCC</smiles>

(E)<smiles>CCCCCCCCCCCCCCCCCCCCCCC(=O)OC</smiles>

(F)<smiles>C/C=C/CCCCCCCCCCCCC</smiles>

(G)

Figure 1. Chemical structures of (A) 3-trifluoroacetoxypentadecane, (B) 13-docosenamide, (C) eicosanal, (D) linoelaidic acid, (E) linoelaidic acid ethyl ester, (F) tricosanoic acid methyl ester, and (G) phytol acetate (structures were drawn using ChemDraw Professional version 16.0). 
Table 1. Quantitative compounds identified from the E. papillosum methanol extract using gas chromatography-mass spectrometry (GC-MS) analysis.

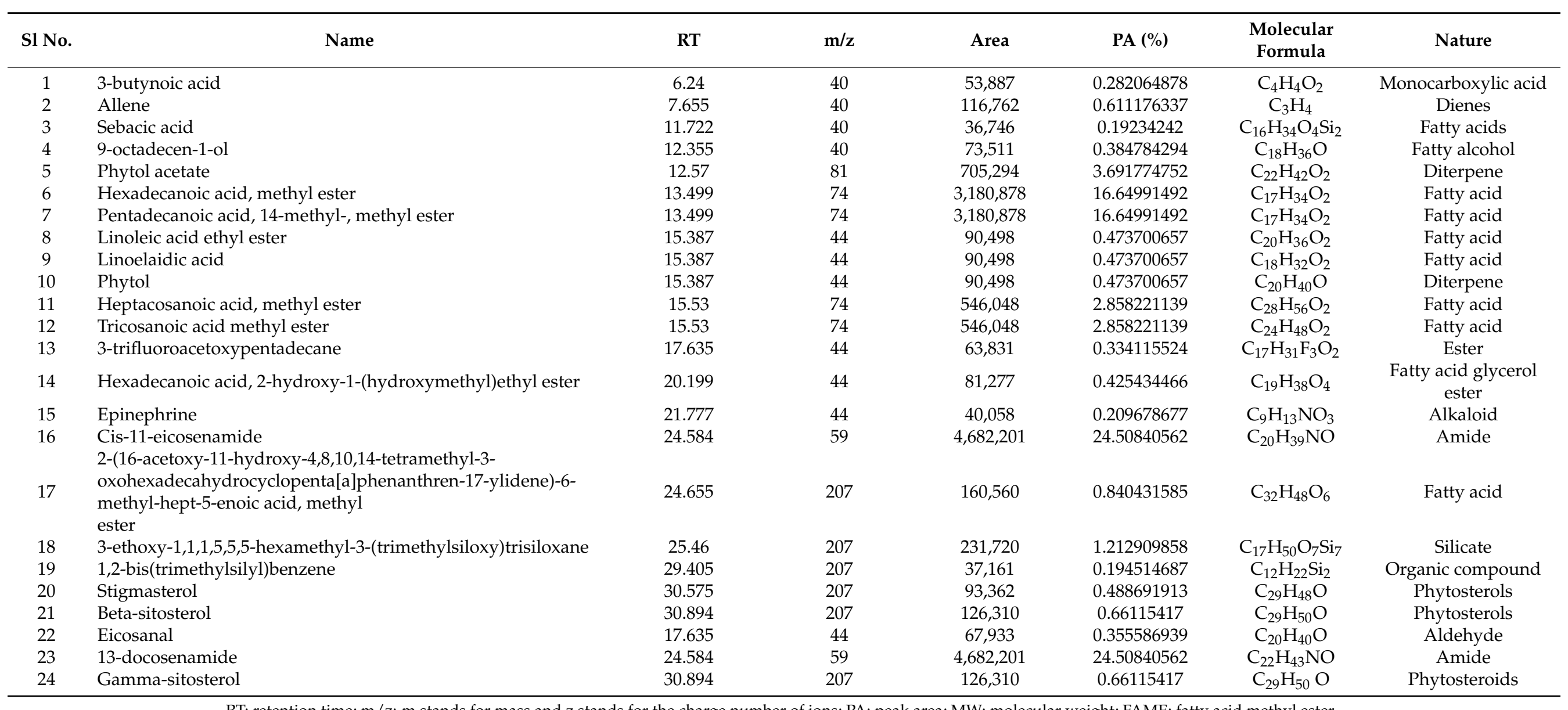

RT: retention time; $\mathrm{m} / \mathrm{z}$ : $\mathrm{m}$ stands for mass and $\mathrm{z}$ stands for the charge number of ions; PA: peak area; MW: molecular weight; FAME: fatty acid methyl ester. 


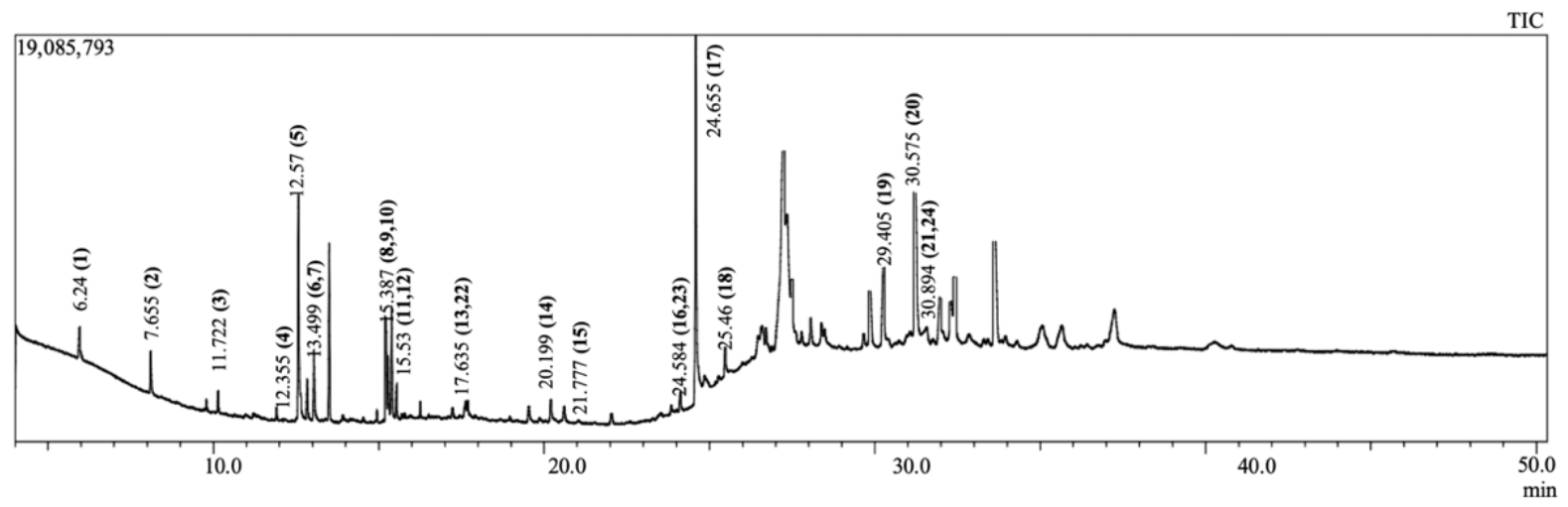

Figure 2. Total ionic chromatogram (TIC) of the whole-plant E. papillosum methanolic extract by gas chromatography-mass spectrometry (GC-MS).

\subsection{Molecular Docking Associated with Antidepressant Activity}

When examining antidepressant properties, the molecular docking simulation study showed docking score ranges from -3.628 to $-0.797 \mathrm{kcal} / \mathrm{mol}$ against human serotonin receptor [Protein Data Bank (PDB) ID: 5I6X], and phytol acetate $(-3.628 \mathrm{kcal} / \mathrm{mol})$ displayed the highest binding affinity, followed by 3-trifluoroacetoxypentadecane $(-3.423 \mathrm{kcal} / \mathrm{mol})$, eicosanal $(-2.525 \mathrm{kcal} / \mathrm{mol})$, and linoelaidic acid $(-0.797 \mathrm{kcal} / \mathrm{mol}$; Table 2$)$. Imipramine was used as a reference drug for antidepressant activity, which exhibited a docking score of $-5.35 \mathrm{kcal} / \mathrm{mol}$, which was greater than all of the selected compounds. In Figure 3 , phytol acetate interacted with our target receptor through the formation of hydrogen bonds with Trp573 and Gln246 residues and the formation of hydrophobic bonds with Trp573, Tyr171, Leu577, Ile581, Leu492, Leu492, Val479, Val473, Val488, and Leu248 residues. In contrast, imipramine $\mathrm{HCl}$ interacted with Tyr171 through hydrogen bonds and interacted with Val479, Leu492, and Ile581 through hydrophobic bonds.

Table 2. Docking score of the selected compounds identified from the E. papillosum methanol extract against the ts 3 human serotonin transporter (PDB ID: 5I6X), potassium channel receptor (PDB ID: 4UUJ), COX-1 (PDB ID: 2OYE), COX-2 (PDB ID: 6COX), NF-kB (PDB ID: 5LDE), and human peroxiredoxin 5 receptor (PDB ID: 1HD2) for antidepressant, anxiolytic, anti-inflammatory, analgesic, and antioxidant activity, respectively.

\begin{tabular}{|c|c|c|c|c|c|c|}
\hline \multirow{2}{*}{ Compounds Name } & \multicolumn{6}{|c|}{ Docking Score (kcal/mol) } \\
\hline & $5 \mathrm{I} 6 \mathrm{X}$ & 4UUJ & COX-1 & COX-2 & 5LDE & 1HD2 \\
\hline 3-trifluoroacetoxypentadecane & -3.423 & -2.512 & -3.458 & - & -4.012 & -1.469 \\
\hline 13-docosenamide & - & - & - & - & - & - \\
\hline Linoelaidic acid & -0.797 & -0.265 & -0.410 & -2.960 & -1.194 & 1.170 \\
\hline Linoleic acid ethyl ester & - & - & - & - & - & - \\
\hline Eicosanal & -2.525 & -3.199 & -3.561 & - & 2.696 & -3.928 \\
\hline Phytol acetate & -3.628 & -2.913 & -3.533 & -5.236 & -4.153 & -1.469 \\
\hline Tricosanoic acid methyl ester & - & - & - & - & - & - \\
\hline $\begin{array}{l}\text { Standard (Imipramine } \mathrm{HCl} \text { / Diazepam/ } \\
\text { Diclofenac-Na/ Ascorbic acid) }\end{array}$ & -5.350 & -4.035 & -4.590 & -7.260 & -5.758 & -5.134 \\
\hline
\end{tabular}




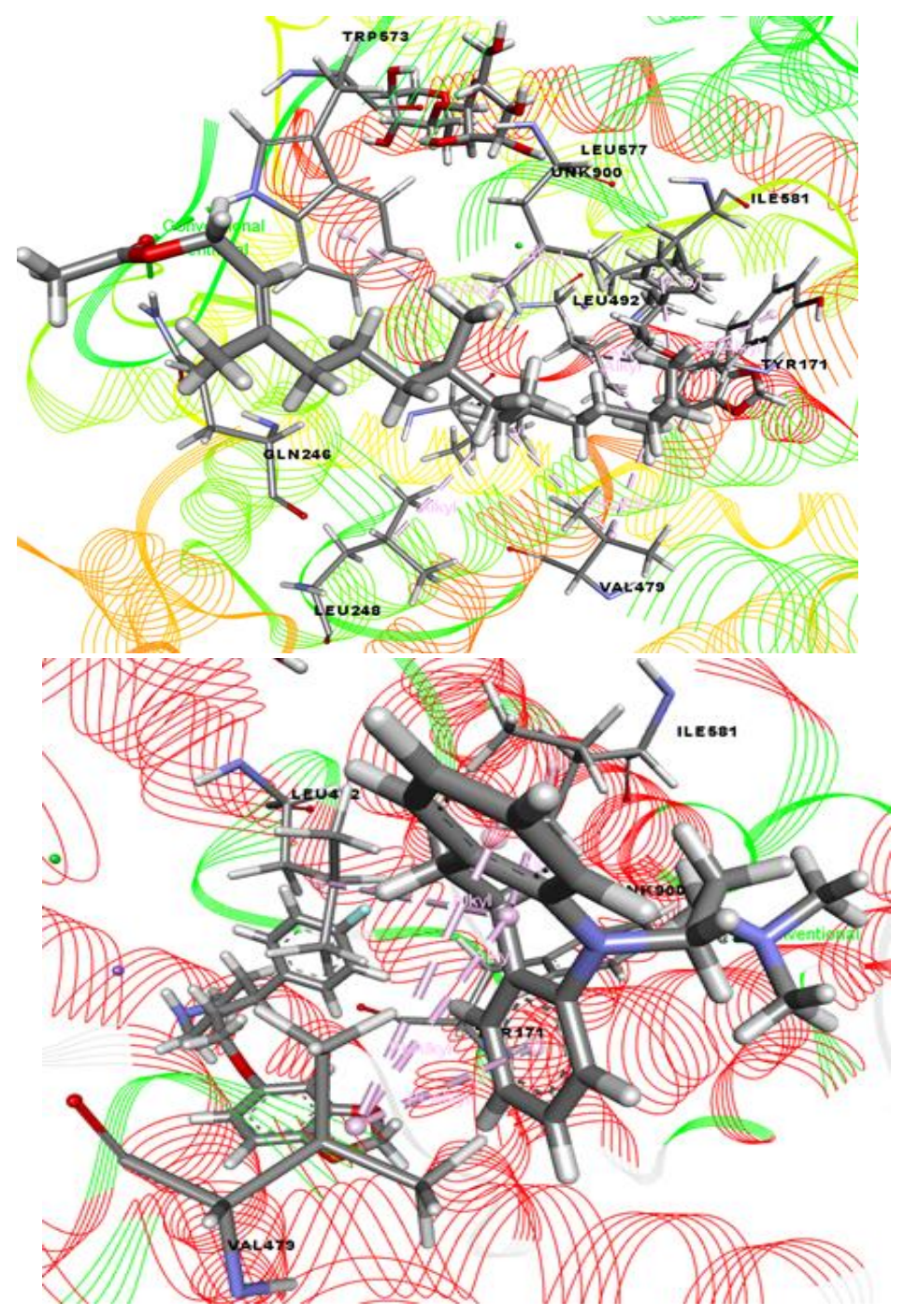

A

Figure 3. Best-ranked poses of phytol acetate (A), and imipramine $\mathrm{HCl}(\mathbf{B})$, in the binding pocket of the ts3 human serotonin transporter (PDB ID: 5I6X). Green color illustrates the residues forming hydrogen bonds, white color illustrates the residues with carbon-hydrogen interaction and pink color illustrates the residues with hydrophobic (pi-pi/pi-alkyl) stacking.

\subsection{Molecular Docking Associated with Anxiolytic Activity}

For the molecular docking simulation study to examine anxiolytic activity, the compounds were docked against the potassium channel receptor (PDB ID: 4UUJ), which resulted in docking scores that ranged from -3.199 to $-0.265 \mathrm{kcal} / \mathrm{mol}$. Eicosanal displayed the highest binding affinity $(-3.199 \mathrm{kcal} / \mathrm{mol})$, followed by phytol acetate $(-2.913 \mathrm{kcal} / \mathrm{mol})$, 3-trifluoroacetoxypentadecane $(-2.512 \mathrm{kcal} / \mathrm{mol})$, and linoelaidic acid $(-0.265 \mathrm{kcal} / \mathrm{mol})$, as shown in Table 2. The three other phytochemicals did not show any interaction with our target receptor, whereas the reference drug diazepam yielded a docking score of $-4.035 \mathrm{kcal} / \mathrm{mol}$. Eicosanal interacted with our target receptor through Asn161, Lys142, and Tyr173 residues. The reference drug diazepam formed various types of hydrophobic bonds with Trp163 (3), Thr164, Asp165, Asp143, and Lys142, as shown in Figure 4. 


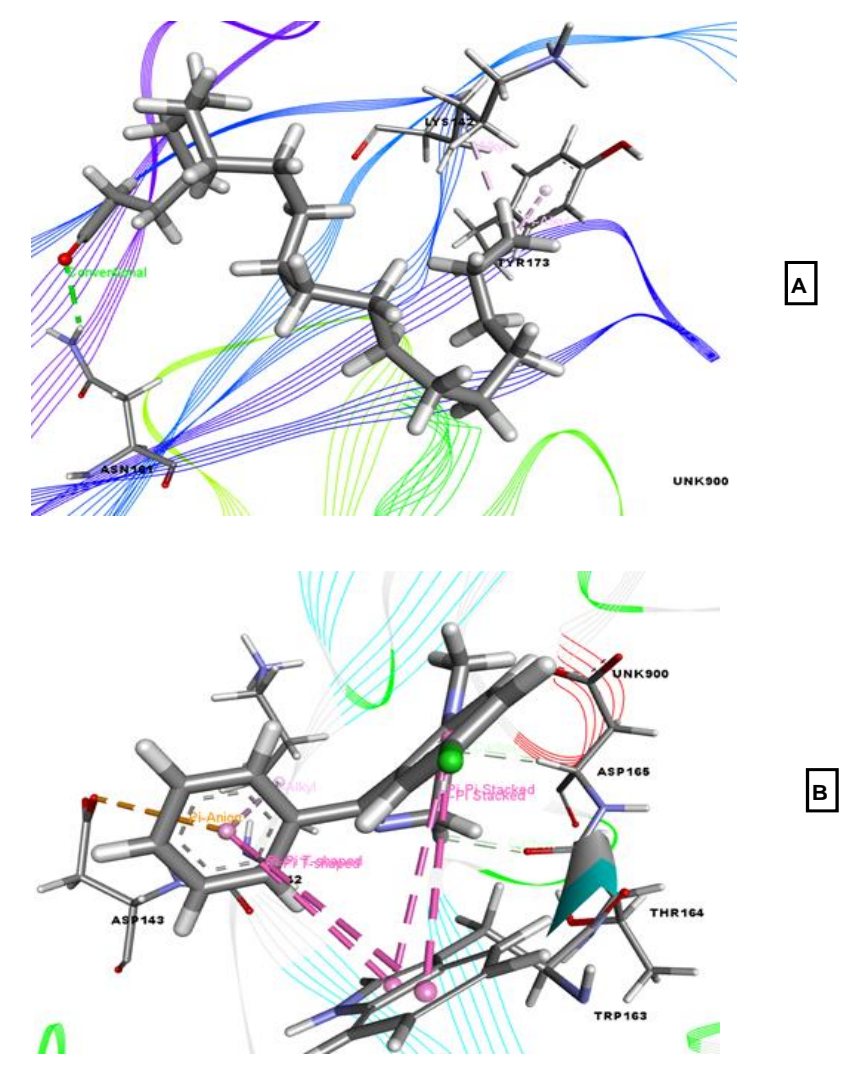

Figure 4. Best-ranked poses for eicosanal (A), and diazepam (B), in the binding pocket of the KcsA potassium channel (PDB ID: 4UUJ). Green color illustrates the residues forming hydrogen bonds, white color illustrates the residues with carbon-hydrogen interaction and pink color illustrates the residues with hydrophobic (pi-pi/pi-alkyl) stacking.

\subsection{Molecular Docking Associated with Analgesic Activity}

The analgesic potentials of the selected compounds were investigated by performing molecular docking studies using the cyclooxygenase-1 (COX-1; PDB ID: 2OYE) and COX-2 (PDB ID: 6COX) receptors as the target proteins. The docking scores of the selected compounds against the COX-1 receptor ranged from -3.561 to $-0.41 \mathrm{kcal} / \mathrm{mol}$. Eicosanal exhibited the best binding affinity $(-3.561 \mathrm{kcal} / \mathrm{mol})$ against COX-1, followed by phytol acetate $(-3.533 \mathrm{kcal} / \mathrm{mol}), 3$-trifluoroacetoxypentadecane $(-3.458 \mathrm{kcal} / \mathrm{mol})$, and linoelaidic acid $(-0.41 \mathrm{kcal} / \mathrm{mol})$. The reference drug diclofenac-Na displayed a docking score of $-4.59 \mathrm{kcal} / \mathrm{mol}$. Eicosanal interacted with the Leu99 and Leu92 residues of our target protein via hydrophobic bonds. Diclofenac-Na interacted with His90, His95, and Pro514 by forming various hydrophobic bonds and formed two hydrogen bonds with His90 and Pro514.

Additionally, phytol acetate exhibited the best binding affinity $(-5.236 \mathrm{kcal} / \mathrm{mol})$ against the COX-2 protein, followed by linoelaidic acid $(-2.96 \mathrm{kcal} / \mathrm{mol})$. None of the other compounds interacted with this target protein. The reference drug diclofenac-Na exhibited a docking score of $-7.26 \mathrm{kcal} / \mathrm{mol}$. Phytol acetate interacted via hydrophobic bonds with Leu352, Leu359, Leu531, Leu93, Val349, Val89, Pro86, and Tyr115 residues. The reference drug formed hydrogen bonds with Arg120 and various hydrophobic bonds with Val349 (2), Leu352, Ser353, Val523, Gly526, and Ala527 (3).

The results of the docking study are shown in Table 2, and the docking figures are presented in Figures 5 and 6. 

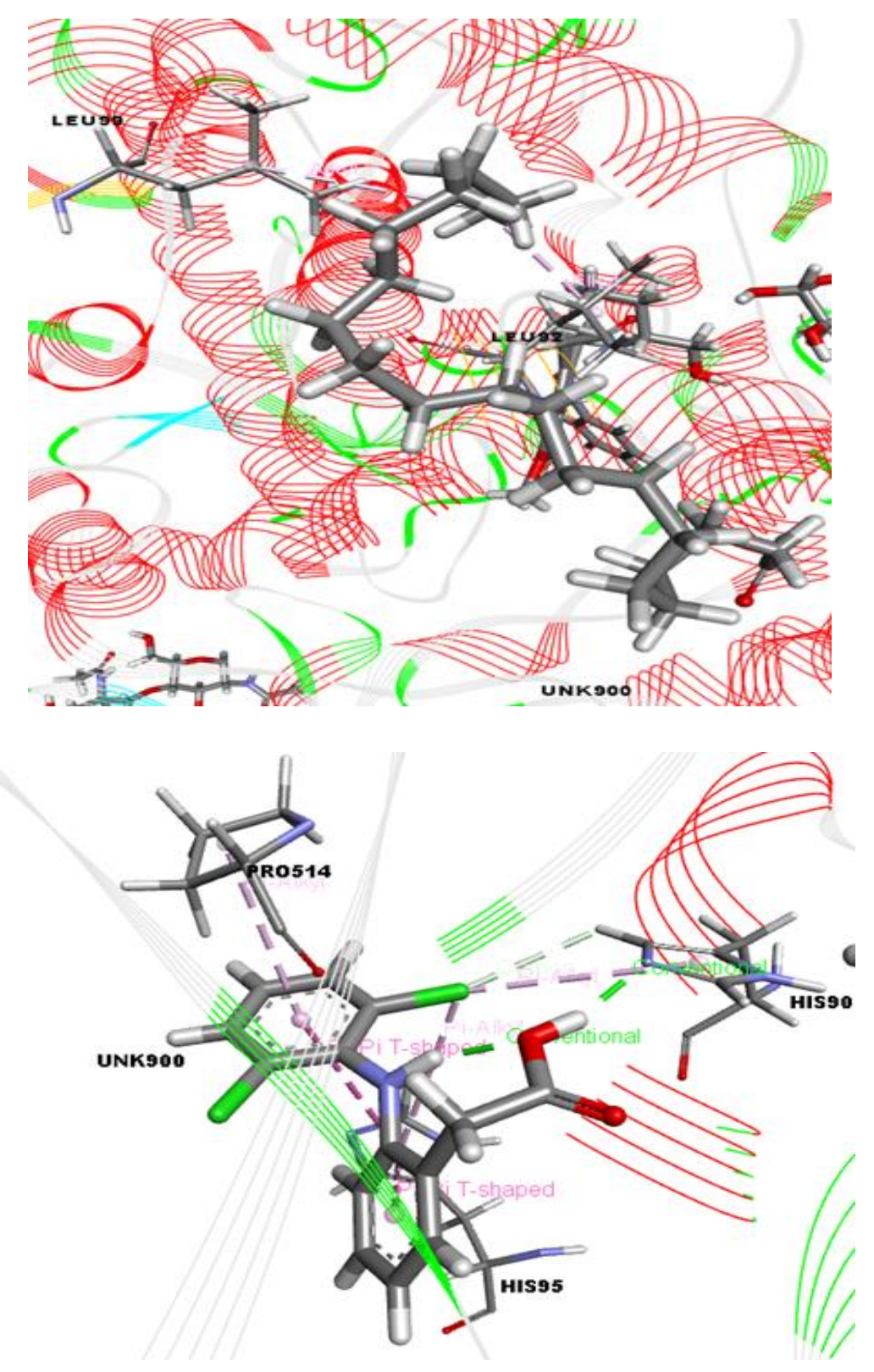

Figure 5. Best-ranked pose of eicosanal (A), and diclofenac-Na (B), in the binding pocket of COX-1 (PDB ID: 2OYE) enzymes. Green color illustrates the residues forming hydrogen bonds, white color illustrates the residues with carbon-hydrogen interaction and pink color illustrates the residues with hydrophobic (pi-pi/pi-alkyl) stacking.

\subsection{Molecular Docking Associated with Anti-Inflammatory Activity}

From the data reported in Table 2 it can be observed that, phytol acetate exhibited the highest binding affinity with nuclear factor kappa-light-chain-enhancer of activated B cells (NF-kB; PDB ID: 5LDE), with a score of $-4.153 \mathrm{kcal} / \mathrm{mol}$, followed by 3-trifluoroacetoxypentadecane $(-4.012 \mathrm{kcal} / \mathrm{mol})$. The reference drug, diclofenac-Na, showed a binding score of $-5.758 \mathrm{kcal} / \mathrm{mol}$. However, 13-docosenamide, linoleic acid ethyl ester, and tricosanoic acid methyl ester did not bind with NF-kB. As shown in Figure 7, phytol acetate interacted with the target protein through Ala34, Ala26, Tyr3, and Lys4 residues. Diclofenac-Na formed hydrophobic bonds with Ala34 and Leu5 and a hydrogen bond with Asp40. 


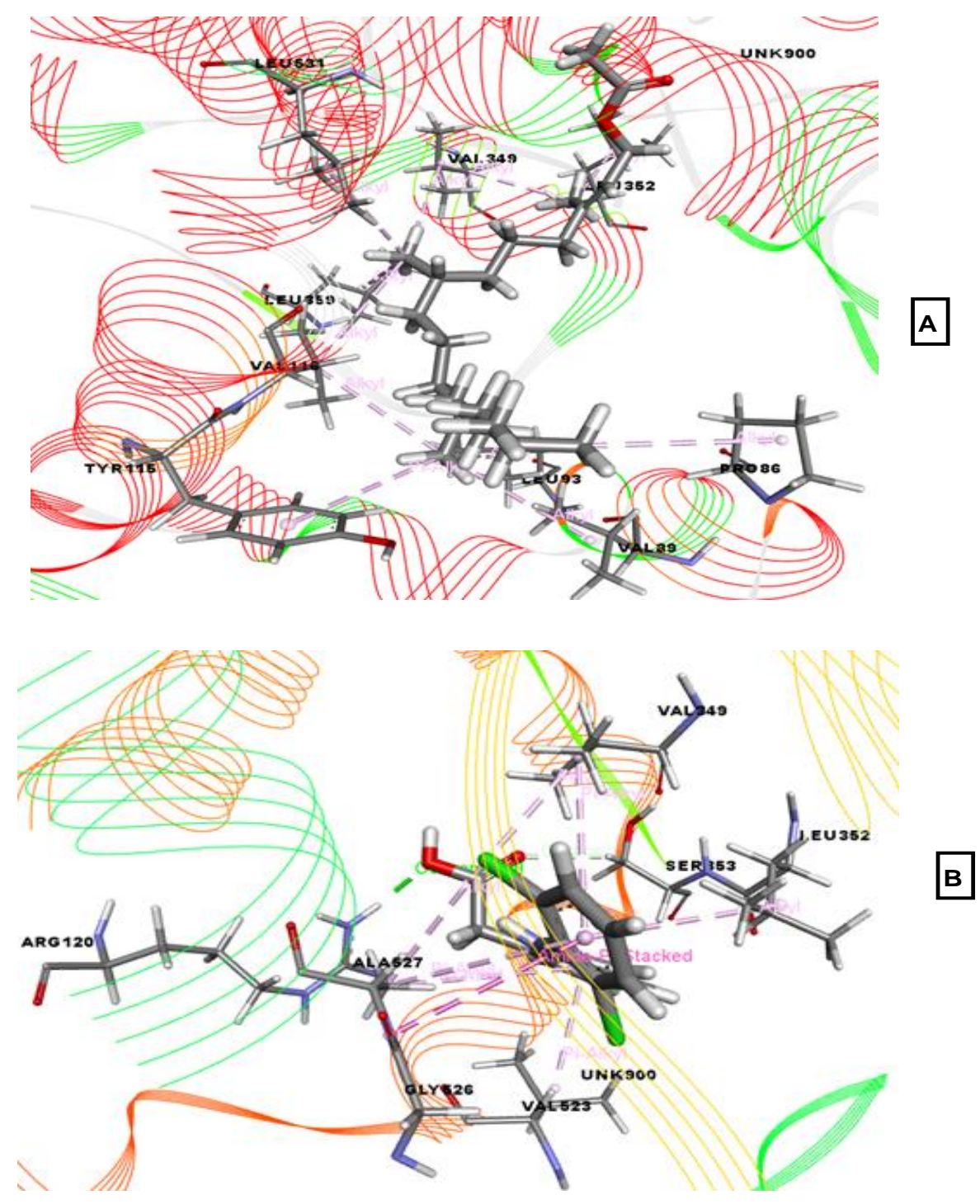

Figure 6. Best-ranked pose of phytol acetate (A), and diclofenac-Na (B), in the binding pocket of COX-2 (PDB ID: 6COX) enzymes. Green color illustrates the residues forming hydrogen bonds, white color illustrates the residues with carbon-hydrogen interaction and pink color illustrates the residues with hydrophobic (pi-pi/pi-alkyl) stacking.

\subsection{Molecular Docking Associated with Antioxidant Activity}

Our study revealed a range of docking scores ranging from -3.928 to $-1.17 \mathrm{kcal} / \mathrm{mol}$ against human peroxiredoxin 5 enzyme (PDB ID: 1HD2) when evaluating potential antioxidant activity (Table 2). Eicosanal possessed the best docking score $(-3.928 \mathrm{kcal} / \mathrm{mol})$, followed by phytol acetate $(-1.469 \mathrm{kcal} / \mathrm{mol})$, 3-trifluoroacetoxypentadecane $(-1.469 \mathrm{kcal} / \mathrm{mol})$, and linoelaidic acid $(-1.17 \mathrm{kcal} / \mathrm{mol})$. Eicosanal interacted with the Lys49 residue of the target protein via hydrogen bond and with the Pro45 residue through hydrophobic interaction. However, ascorbic acid, which was used as a reference drug for antioxidant activity, exhibited the highest docking score of $-5.134 \mathrm{kcal} / \mathrm{mol}$, interacting with Arg176 (2), His256 (2), Asn254, Val227, and Gln228 via hydrogen bonds (Figure 8). 

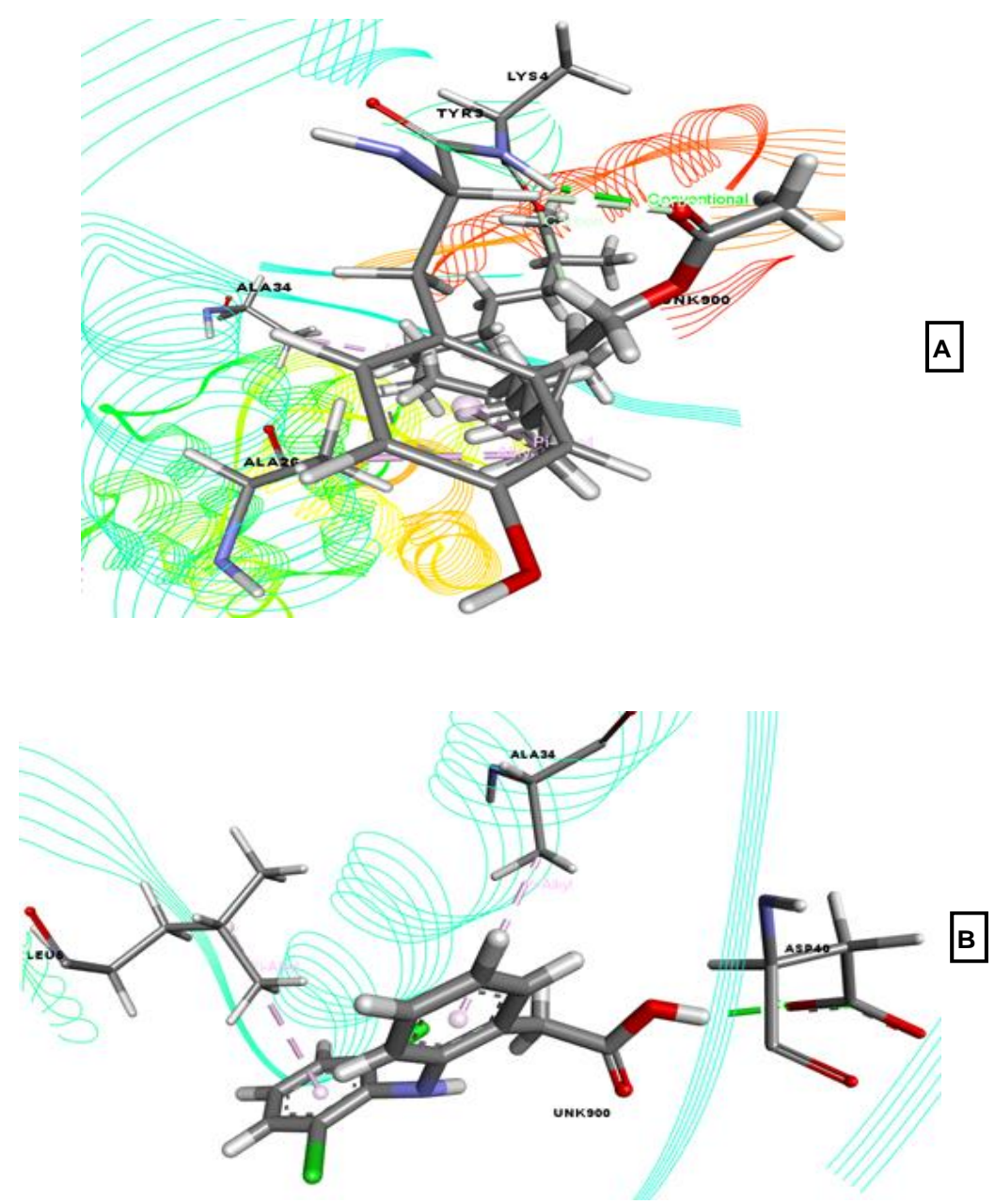

Figure 7. Best-ranked poses for phytol acetate (A), and diclofenac-Na (B), in the binding pocket of nuclear factor kappa-light-chain-enhancer of activated B-cells (NF-kB; PDB ID: 5LDE). Green color illustrates the residues forming hydrogen bonds, white color illustrates the residues with carbon-hydrogen interaction and pink color illustrates the residues with hydrophobic (pi-pi/pialkyl) stacking.

\subsection{Ligand-Based ADME/T Predictions}

The seven selected bioactive compounds were screened for drug-candidacy by evaluating their pharmacokinetic and physicochemical properties using the QikProp module of Schrödinger Suite-Maestro, version 10.1. The range of different ADME (absorption, distribution, metabolism, and excretion) parameters that were evaluated included the molecular weight, the estimated number of hydrogen bond donors (HB donors) and acceptors (HB acceptors) in the solute when combined with water molecules in an aqueous solution, and the total solvent accessible surface area (SASA) value. These values for all compounds were found to be within the acceptable ranges. These compounds also demonstrated good brain/blood partition coefficient $(\mathrm{QPlogBB})$ values, ranging from -1.523 to 0.25 , which suggested that the compounds are within acceptable limits. The values of the octanol/water partition coefficient (QPlog Po/w) ranged from 4.826 to 7.528. The aqueous solubility (QPlogS) values for the selected compounds ranged from -13.069 to -5.802. All of the selected compounds fulfilled Lipinski's rule of five (RO5), with none of the compounds contravening more than one of Lipinski's rules (Table 3). The selected compounds displayed high percentages of human oral absorption, with all exceeding $80 \%$, and most of the phytochemicals exhibited $100 \%$ oral absorption. 

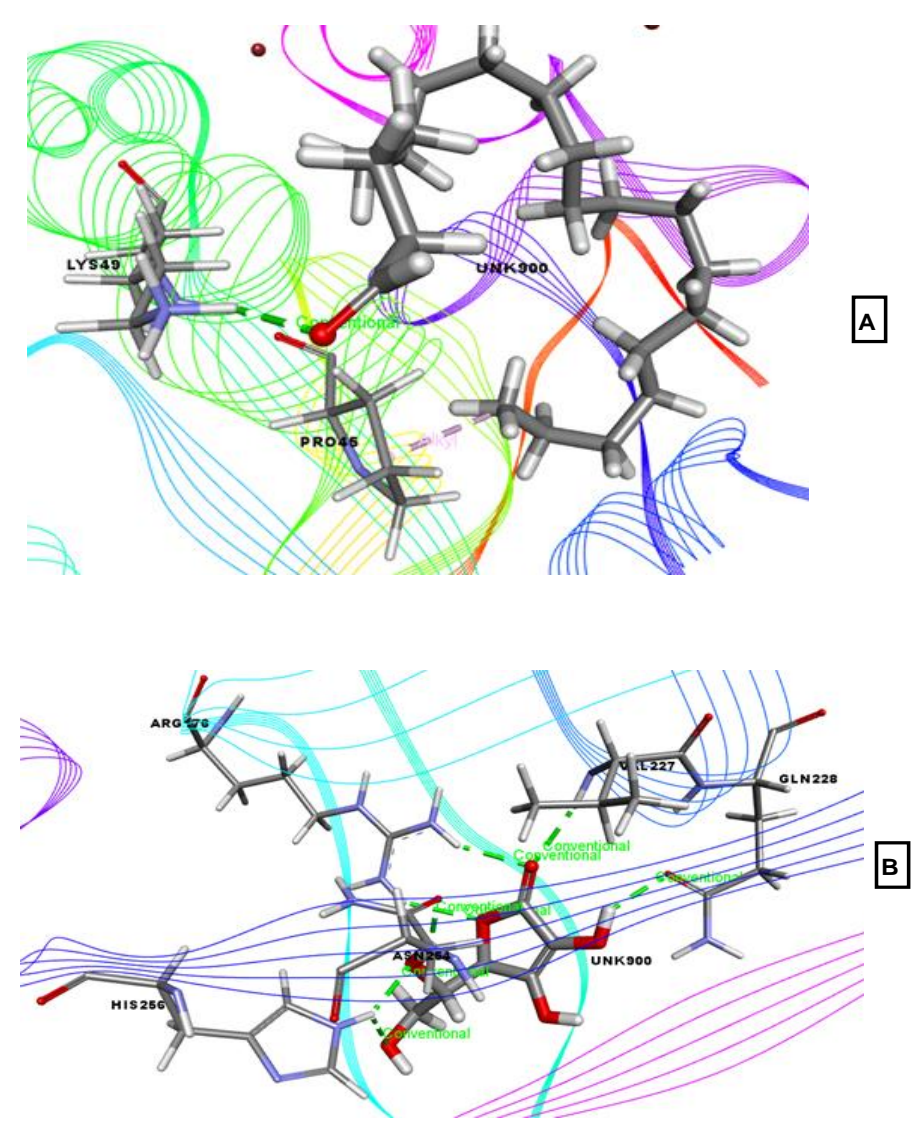

Figure 8. Best-ranked pose for eicosanal (A), and ascorbic acid (B), in the binding pocket of human peroxiredoxin 5 (PDB ID: 1HD2). Green color illustrates the residues forming hydrogen bonds, white color illustrates the residues with carbon-hydrogen interaction and pink color illustrates the residues with hydrophobic (pi-pi/pi-alkyl) stacking.

Table 3. ADME and drug-likeness properties of 3-trifluoroacetoxypentadecane, 13-docosenamide, linoelaidic acid, linoelaidic acid ethyl ester, eicosanal, phytol acetate, and tricosanoic acid methyl ester, as determined by QikProp.

\begin{tabular}{|c|c|c|c|c|c|c|c|c|}
\hline $\begin{array}{l}\text { Compound } \\
\text { Name }\end{array}$ & $\mathbf{M W}^{\mathrm{a}}$ & $\begin{array}{c}\text { HB } \\
\text { Donors }\end{array}$ & $\begin{array}{c}\text { HB } \\
\text { Acceptors }\end{array}$ & SASA $^{\mathrm{d}}$ & QPlogPo/w ${ }^{e}$ & $Q P \log B B{ }^{f}$ & QPlogS g & $\begin{array}{c}\text { \%Human } \\
\text { Oral } \\
\text { Absorption }\end{array}$ \\
\hline $\begin{array}{l}\text { 3- } \\
\text { trifluoroacetoxy } \\
\text { pentadecane }\end{array}$ & 324.426 & 0 & 2 & 721.905 & 6.548 & -0.338 & -7.253 & 100 \\
\hline $\begin{array}{c}13- \\
\text { docosenamide }\end{array}$ & 337.588 & 2 & 3 & 864.813 & 5.197 & -0.461 & -9.339 & 88.609 \\
\hline $\begin{array}{l}\text { Linoelaidic } \\
\text { acid }\end{array}$ & 280.45 & 1 & 2 & 717.95 & 5.83 & -1.523 & -6.373 & 90.462 \\
\hline $\begin{array}{l}\text { Linoleic acid } \\
\text { ethyl ester }\end{array}$ & 308.503 & 0 & 3 & 670.733 & 4.826 & 0.25 & -7.357 & 100 \\
\hline Eicosanal & 296.535 & 0 & 2 & 838.966 & 6.518 & -0.086 & -11.068 & 100 \\
\hline $\begin{array}{l}\text { Phytol } \\
\text { acetate }\end{array}$ & 338.573 & 0 & 2 & 681.355 & 6.661 & -0.623 & -5.802 & 100 \\
\hline $\begin{array}{l}\text { Tricosanoic } \\
\text { acid methyl } \\
\text { ester }\end{array}$ & 368.642 & 1 & 3 & 977.143 & 7.528 & 0.138 & -13.069 & 100 \\
\hline
\end{tabular}

${ }^{a}$ Molecular weight (acceptable range: $\left.<500\right) .{ }^{b}$ Hydrogen bond donor (acceptable range: $\left.\leq 5\right) .{ }^{c}$ Hydrogen bond acceptor (acceptable range: $\left.\leq 10\right)$. $\mathrm{d}$ Total solvent accessible surface area using a probe with a 1.4 radius (acceptable range: $300-1000) . ~{ }^{\mathrm{e}}$ Predicted octanol/water partition coefficient (acceptable range: $-2-6.5) .{ }^{\mathrm{f}}$ Predicted blood-brain partition coefficient (acceptable range: $\left.-3-1.2\right)$. ${ }^{\mathrm{g}}$ Predicted aqueous solubility, $\mathrm{S}$ in $\mathrm{mol} / \mathrm{dm}^{-3}$ (acceptable range: $-6.5-0.5) .{ }^{\mathrm{h}}$ Predicted human oral absorption on 0 to $100 \%$ scale $(<25 \%$ is poor and $>80 \%$ is high). 


\subsection{Molecular Mechanics Generalized Born Surface Area (MM-GBSA) Analysis and Ligand Efficiency}

In Table 4 , the compounds showing MM-GGBSA $\Delta$ G bind against particular receptors. There was a good correlation between MMGBSA $\Delta \mathrm{G}$ bind and binding affinity. We also report on the use of an in silico approach to predict the binding affinities and ligand efficiencies of E. papillosum constituents towards distinct receptors.

Table 4. Binding affinity $(\mathrm{kcal} / \mathrm{mol})$ and ligand efficiencies estimation of the best docked compounds and the standard drugs.

\begin{tabular}{ccc}
\hline Compound Name/Standard & MM-GBSA $\Delta$ G Bind & Ligand Efficiency \\
\hline & Antidepressant Activity & \\
\hline Phytol acetate & -72.00 & 3.00 \\
Imipramine HCl (Standard) & -49.18 & 2.24 \\
\hline \multicolumn{3}{c}{ Anxiolytic Activity } \\
\hline Anti-inflammatory Activity Cyclooxygenase-1 (COX-1) \\
Phenobarbital (Standard) & -42.06 & 2.00 \\
\hline Eicosanal & -37.86 & 1.80 \\
\hline Diclofenac-Na (Standard) & Cyclooxygenase-2 (COX-2) & 2.28 \\
\hline Phytol acetate & -75.25 & 1.87 \\
\hline Diclofenac-Na (Standard) & -54.64 & 3.14 \\
\hline Phytol acetate & NF-kB & 2.73 \\
\hline Diclofenac-Na (Standard) & -88.59 & 3.69 \\
\hline & -52.91 & 2.65 \\
\hline Eicosanal & Antioxidant Activity & 2.33 \\
\hline
\end{tabular}

\subsection{Molecular Dynamics Simulations}

The root-mean-square deviations of the drug-protein complexes were explored to examine the steady-state characteristics of the complexes. Figure 9A demonstrates that the compound with the best analgesic activity did not display any fluctuations throughout the entire simulation time, exhibiting a steady conformation. The control 1 antioxidant and anxiolytic and control 2 showed less deviation, although they initially displayed a high level of flexibility subsequently but stabilized. The control 3 and analgesic complexes displayed larger changes during the initial phase but did not exceed an RMSD value above 2.5 $\AA$. The RMSD descriptors from eight complexes in Figure 9A correlates with the stability of the complexes.

The hydrogen bond formations observed during the simulation define the overall integrity of the complexes. A higher degree of changes observed in the hydrogen bond patterning indicates complex instability and increased flexibility. The hydrogen bonds depicted in Figure 9B showed that all eight complexes between the tested compounds and the target protein displayed stable hydrogen bonding patterns, with no significant changes in the hydrogen bond numbers observed, suggesting that all eight complexes maintained structural integrity. 
A

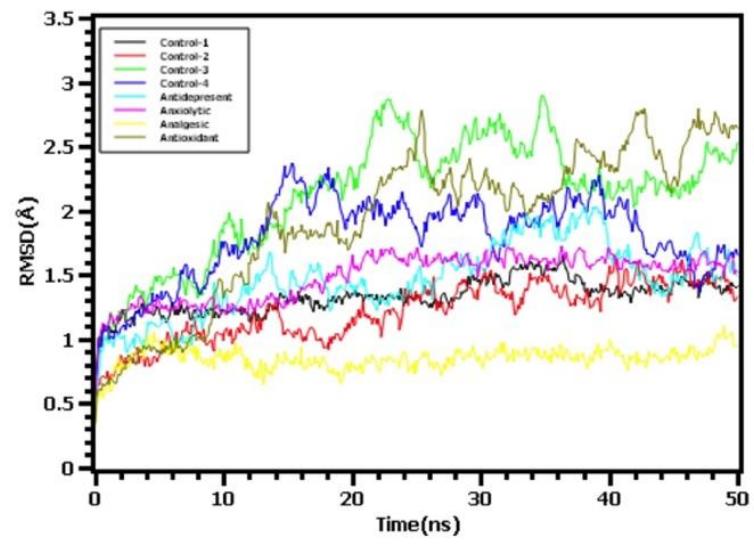

$B$

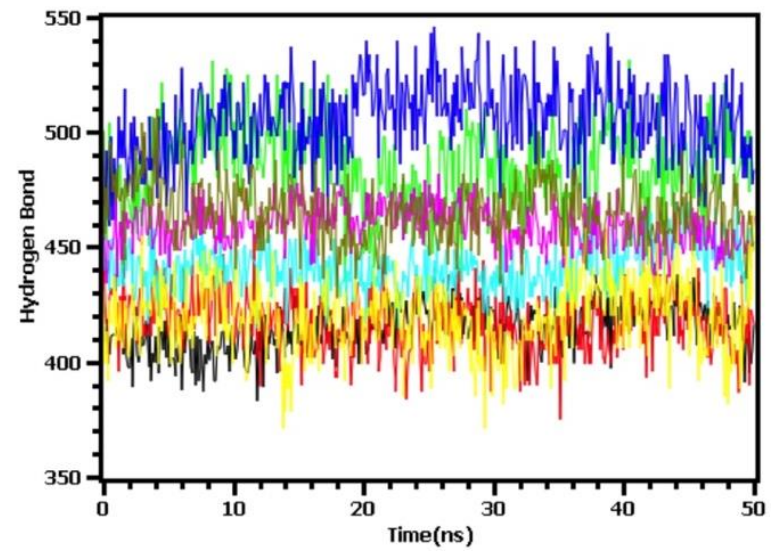

Figure 9. The molecular dynamics simulation study of the docked complex. (A) Root mean square deviation (RMSD), and (B) hydrogen bond patterns were assessed from the simulation trajectories. Phytol acetate (5I6X) was compared against imipramine $\mathrm{HCl}$ (control 1), eicosanal (4UUJ) was compared against diazepam (control 2), phytol acetate (5LDE) was compared against diclofenac-Na (control 3), and eicosanal (1HD2) was compared against ascorbic acid (control 4).

\section{Discussion}

Recently, plant-derived substances have garnered significant interest because of their remarkable applications. Medicinal plants are the richest bioresources for conventional drugs, modern medicines, nutraceuticals, curative intermediates, and artificial drug chemicals. Medicinal plants have also been used by human society to combat diseases since the dawn of civilization. A large portion of the population, especially those who live in rural communities, largely depends on herbal remedies. Several herbal remedies have withstood the test of time, particularly those used to treat allergic, metabolic, and degenerative diseases associated with aging. However, scarce scientific data regarding the chemical identities and effectiveness of these herbs are available, except those associated with the practice of Ayurveda and Unani medicine $[8,13]$. In this study, we conducted a correlation study between our previously reported bioactivities and a computer-aided molecular docking study to provide evidence to support the traditional and novel therapeutic use of E. papillosum. Although phytochemicals obtained from medicinal plants were focused on the empiric experience in the past, currently, the scientific evidence regarding the chemical composition and therapeutic properties are regarded as the main focus while isolating several phytochemicals. Expert taxonomists mainly perform the identification and authentication of medicinal plants; however, one of the main disadvantages includes the absence of several phenotypic characteristics. In addition, the products used in traditional medicine are processed in various forms, such as powder, extracts, capsules, and tablets. Phytochemical characterization could therefore be used in the identification and authentication of several medicinal plants [20-25].

Molecular docking has become a widely employed tool in the field of computer-aided drug design because molecular docking allows for binding predictions to be made between small compounds and large macromolecules and various target proteins [26]. Molecular docking can also be utilized to understand the probable mechanisms of action for different pharmacological activities [27]. Several studies have recently used molecular docking analysis to predict the binding mode of numerous phytochemicals obtained from several medicinal plant extracts with the respective receptors for various pharmacological activities $[17,28]$. In our present study, we implemented a molecular docking analysis to explore the binding affinities of selected compounds against various target proteins. Eicosanal and phytol acetate are the two compounds that have displayed the best interactions with a variety of target proteins to exert a various pharmacological activities (antioxidant, antide- 
pressant, anxiolytic, analgesic, and anti-inflammatory activities). Eicosanal displayed the highest binding affinity against the target proteins examined to assess analgesic, anxiolytic, and antioxidant activity, whereas phytol acetate displayed the best docking scores against the target proteins examined to assess analgesic, anti-inflammatory, and antidepressant activity.

Pharmacologically, COX-1 and COX-2 are responsible for the formation of prostanoids, which act in several pathways [29,30]. In general, the synthesis of prostanoids is mediated by phospholipase $\mathrm{A}_{2}$, which regulates the release of arachidonic acid from membrane phospholipids $[4,31]$. Therefore, COX inhibition correlates not only with the pharmacological inhibition of various downstream biochemical effects but also inhibits the synthesis of prostaglandins (PGs) [31]. In our current study, the targeted compounds interacted with both COX-1 and COX-2; however, the interactions were weaker than that for the positive control used in the study. Despite having a lower docking score, eicosanal interacted with the Leu92 residue through hydrophobic interaction. A recent study documented that the Leu92 residue is responsible for stabilizing the structure. Similar results were observed during the interaction with COX-2 and the targeted compounds, for which diclofenac-Na possessed the highest docking score. However, phytol acetate interacted with COX-2 by forming a hydrophobic interaction with several residues, including Leu352, Leu359, Leu531, Leu93, Val349, Val89, Pro86, and Tyr115. A previous study by Krisnamurti et al. reported that acetaminophen binds with Leu352 and Val349 through hydrophobic interactions and may interfere with the COX-2 activity [32]. In addition, NF- $\mathrm{KB}$ has been viewed as a prominent target for anti-inflammatory and analgesic responses [33,34]. In the present experiment, phytol acetate interacted with NF- $\mathrm{kB}$ with the greatest affinity. Previously, NF- $\mathrm{kB}$ inhibition was shown to be mediated by phytol acetate found in the hexane extract of Cymbopogon citratus [35].

To perform the in silico analysis of potential anxiolytic and antidepressant activities, we selected the potassium channel receptor and the human serotonin receptor, respectively. Potassium channels regulate the excitability of neurons, and the serotonin receptor is strongly associated with the etiology and pharmacology of depression [36,37]. Our previous study demonstrated the inhibition of both receptors by selective phytocompounds isolated from Piper sylvaticum plant extract [38]. Moreover, we also analyzed the antioxidant effects of the selected phytocompounds by performing a molecular docking analysis using the human peroxiredoxin 5 enzyme. Here, eicosanal interacted with the Lys49 residue by forming a hydrogen bond, which agrees with the results of a previous study by Bharati et al. [39].

In addition to molecular docking simulations, ADME/T analyses were performed. In the recent era, drug design and discovery approaches have shifted from phenotypic screens to high throughput screening and combinatorial chemistry. Thus, the physicochemical properties are concerned as remarkable characteristics during the selection of drug molecules, which displayed a shift towards higher molecular weight and lipophilicity. The ADME/T analysis using the "rule of five" (RO5) is currently recognized as a widespread marker during drug designing that depicts the solubility profile and permeability. The selected phytocompounds were further analyzed using the QikProp module of the Schrödinger suite-Maestro, version 10.1, to explore their drug-likeness behaviors and their physicochemical and pharmacokinetic characteristics. Compounds that contravene any of Lipinski's RO5 may encounter problems due to permeability, absorption, and bioavailability, as ligand molecules with lower molecular weights, hydrogen bond capacities, and lipophilicity typically exhibit better permeability [40], faster absorption, and higher bioavailability [41,42]. According to Lipinski's RO5, our selected phytocompounds displayed good orally-active drug-candidacy profiles. Additionally, assessments of the abilities of the drugs to pass through the blood-brain barrier (QPlogBB), the total SASA, and the percent human oral absorption also indicated that these compounds might be considered as potential drug molecules with receptor-based optimization. 


\section{Materials and Methods}

\subsection{Preparation of Crude Methanolic Extract}

Whole plant parts of E. papillosum were collected from Chittagong district $\left(22^{\circ} 36^{\prime} 00^{\prime \prime} \mathrm{N}\right.$, $91^{\circ} 40^{\prime} 14.13^{\prime \prime}$ E) of Bangladesh. The plants were sun dried for several days and then oven dried for $24 \mathrm{~h}$ at considerably low temperature (below $40{ }^{\circ} \mathrm{C}$ ) to facilitate grinding. The powdered material $(500 \mathrm{~g})$ was macerated in $2.5 \mathrm{~L}$ of methanol for 15 days and then filtered through a cotton plug followed by Whatman filter paper number 1 . The extract was concentrated with a rotary evaporator (RE 200, Bibby Sterling Ltd., UK) at low temperature $\left(40-45^{\circ} \mathrm{C}\right)$ and reduced pressure. The viscous mass was stored in a refrigerator $\left(4{ }^{\circ} \mathrm{C}\right)$ for future use.

\subsection{Gas Chromatography-Mass Spectrometry (GC-MS) Analysis}

The methanolic leaf extract of E. papillosum was inspected using a mass spectrometer (TQ 8040, Shimadzu Corporation, Kyoto, Japan) using the electron impact ionization method, and a gas chromatograph (GC-17A, Shimadzu Corporation) fused with silica capillary column (Rxi-5 ms; $0.25 \mathrm{~m}$ film, $30 \mathrm{~m}$ long, and internal diameter: $0.32 \mathrm{~mm}$ ) coated with DB-1 (J\&W). The oven temperature was programmed as $70^{\circ} \mathrm{C}(0 \mathrm{~min})$ increasing to $150{ }^{\circ} \mathrm{C}$, at $10^{\circ} \mathrm{C} / \mathrm{s}$. with a hold time of $10 \mathrm{~min}$. A $260^{\circ} \mathrm{C}$ temperature was maintained as the inlet temperature. The flow rate was set to a speed of $0.6 \mathrm{~mL} / \mathrm{min}$, using helium gas at a $90 \mathrm{kPa}$ constant pressure. The interface temperature from GC to MS was maintained at a constant $280^{\circ} \mathrm{C}$. The MS was set in scan mode with a scanning range of $40-350 \mathrm{amu}$; the ionization mode was EI (electron ionization) type. The injection volume of the sample was one microliter. The entire GC-MS procedure lasted for $50 \mathrm{~min}$ [31]. A comparison with the National Institute of Standards and Technology (NIST) GC-MS library version 08-S was performed to identify the compounds in the peak areas

\subsection{Computational Molecular Docking Analysis \\ 4.3.1. Chemical Compounds Studied}

Seven bioactive compounds were selected for molecular docking analysis, and the PubChem database (https:/ / pubchem.ncbi.nlm.nih.gov (accessed on 7 February 2021)) was used to download the structures of the compounds. The selected compounds were 3-trifluoroacetoxypentadecane (PubChem CID: 534406), 13-docosenamide, (Z)-(PubChem CID: 5365371), linoelaidic acid (PubChem CID: 5282457), linoleic acid ethyl ester (PubChem CID: 5282184), eicosanal (PubChem CID: 75458), phytol acetate (PubChem CID: 6428538), and tricosanoic acid methyl ester (PubChem CID: 75519) (see Figure 1).

\subsubsection{Preparation of Ligand}

The chemical structures of the seven compounds that were isolated by GC-MS analysis were downloaded from PubChem. The structures were neutralized at $\mathrm{pH} 7.0 \pm 2.0$ and minimized by force field OPLS 2005 embedded in Schrödinger Suite-Maestro, version 10.1.

\subsubsection{Preparation of Receptor/Enzymes}

Three-dimensional crystallographic enzyme structures were obtained from the PDB [43]: KcsA potassium channel (PDB ID: 4UUJ), ts3 human serotonin transporter (PDB ID: 5I6X) [44], human peroxiredoxin 5 (PDB ID: 1HD2) [45], NF-kB (PDB ID: 5LDE), COX-1 (PDB ID: 2OYE) and COX-2 (PDB ID: 6COX) [46-49]. The enzymes were prepared for the docking experiment by the Protein Preparation Wizard embedded in Schrödinger Suite-Maestro, version 10.1.

\subsubsection{Glide Docking}

A molecular docking study was performed to interpret the potential mechanisms of the selected compounds against several suitable proteins associated with anxiolytic, antidepressant, antioxidant, analgesic, and anti-inflammatory activities. Docking analy- 
sis was performed using Maestro by standard precision scoring function, as previously described [50,51].

\subsection{Ligand-Based Pharmacokinetic Parameter Analysis}

The QikProp module of the Schrödinger Suite-Maestro, version 10.1, is a quick, precise, easy-to-use, online-based program designed to predict significant pharmacokinetic and physicochemical descriptors linked to ADME properties. QikProp evaluates the admissibility of ADME properties to ascertain the drug-likeness of selected ligand molecules, based on Lipinski's RO5. The ADME/T properties of the selected bioactive compounds (3-trifluoroacetoxy pentadecane, 13-docosenamide, linoelaidic acid, linoleic acid ethyl ester, eicosanal, phytol acetate, and tricosanoic acid methyl ester) were analyzed using the QikProp 3.2 module [52].

\subsection{Prime Molecular Mechanics Generalized Born Surface Area (MM-GBSA) and Ligand Efficiency}

Prime MM-GBSA approach was used to calculate ligand-binding energies and ligand strain energies for a ligand and a receptor. The Prime MM-GBSA module from the Schrodinger software package was utilized to calculate the binding affinity. MM-GBSA is a method that amalgams OPLS 2005 molecular mechanics energies (EMM), an SGB solvation model for polar solvation (GSGB), and a nonpolar solvation term (GNP) composed of the nonpolar solvent surface area and Van der Waals interactions. The higher degree of rigidity of the ligand attached protein is indicated by the higher negative MM-GBSA value. The Prime MM-GBSA process consists of three different approaches; OPLS molecular mechanics energies, an SGB solvation model, and a nonpolar solvent [53]. The binding free energies were calculated from the following equations:

$$
\Delta \mathrm{G}_{\text {bind }}=\mathrm{G}_{\text {complex }}-\left(\mathrm{G}_{\text {protein }}+\mathrm{G}_{\text {ligand }}\right),
$$

where

$$
\mathrm{G}=\mathrm{EMM}+\mathrm{VSGB}+\mathrm{GNP} .
$$

Therefore, to perceive their rigidity along with motion and structural stability in simulation conditions, the best three ligands are selected for further processing. For each ligand, the ligand efficiency was also calculated using the ratio of $\Delta \mathrm{G}$ to the number of heavy atoms (NHA) for each ligand, ligand efficiency $=-(\Delta \mathrm{G}) / \mathrm{NHA})$.

\subsection{Computational Molecular Dynamic Simulations Analysis}

The molecular dynamics simulation of the docked complexes was analyzed in YASARA dynamics to evaluate the conformational variations [54]. The AMBER14 force field [55] was used, and the complexes were initially cleaned and optimized. The Particle Mesh Ewald method was applied to calculate the long-range electrostatic interactions [56]. The periodic boundary condition was maintained, and the system was neutralized with the addition of $0.9 \% \mathrm{NaCl}, 7.4 \mathrm{pH}$ at a temperature of $36^{\circ} \mathrm{C}$. The Berendsen thermostat was used to maintain the temperature of the simulation cell [57]. The simulation cell was extended $20 \AA$ beyond the complexes, providing more flexibility. The normal simulation time step of $1.25 \mathrm{fs}$ was maintained. The simulation trajectories were saved after every 100-ps interval, and the simulation was run for 50-ns to analyze RMSD and root mean square fluctuation (RMSF) $[58,59]$. Imipramine $\mathrm{HCl}$, diazepam, diclofenac-Na, and ascorbic acid were denoted as control 1, control 2, control 3, and control 4, respectively.

\section{Conclusions}

To the best of our knowledge, this is the first report describing an in silico correlation between the predicted pharmacological activities of E. papillosum and the chemical compounds that characterize its methanolic extract. However, further studies remain necessary to elucidate the mechanisms underlying these effects. Previously, no data regarding this 
plant has been published; therefore, we believe that E. papillosum may be an exemplary sample for alternative therapeutic sources. It is necessary to characterize the structures of secondary metabolites found in the plant and to highlight novel compounds as potential therapeutic components. Thus, this contemporary research can offer some preliminary pharmacological evidence for the ethnomedical uses of E. papillosum and it reveals that this plant contains some active agents that may be responsible for these activities.

Author Contributions: Conceptualization, M.Z.U., A.P., A.R., T.B.E. and J.S.-G.; methodology, M.Z.U., A.P., A.R. and S.A.S.; software, A.P., A.R., S.A.S. and S.M.; validation, M.Z.U., A.P., M.S.R., T.B.E. and J.S.-G.; formal analysis, M.S.R., S.H., S.M., A.M.T., M.D., T.B.E. and J.S.-G.; investigation, M.Z.U., A.P., A.R., S.M. and M.D.; resources, J.S.-G.; data curation, M.Z.U., A.R., A.P., S.A.S.; writing—original draft preparation, M.Z.U., A.R., A.P., A.M.T., T.B.E. and J.S.-G.; writing—review and editing, M.Z.U., A.P., A.R., M.S.R., S.H. and J.S.-G.; visualization, M.Z.U., A.P., A.R., M.D. and T.B.E.; supervision, M.S.R., S.H., T.B.E. and J.S.-G.; project administration, M.S.R., S.H., T.B.E. and J.S.-G.; funding acquisition, T.B.E. and J.S-G. All authors have read and agreed to the published version of the manuscript.

Funding: This research received no external funding.

Institutional Review Board Statement: Not applicable.

Informed Consent Statement: Not applicable.

Data Availability Statement: Available data are presented in the manuscript.

Conflicts of Interest: The authors declare no conflict of interest.

\section{References}

1. Mamun-Or-Rashid, M.; Islam, M.A.; Idris, T.; Amran, M.S. CNS-Antidepressant Activity of Crude Extracts and Different Fractions of Stem Bark of Acacia Nilotica. Pharm. Sci. Technol. 2017, 1, 13.

2. Reynolds, E. Brain and mind: A challenge for WHO. Lancet 2003, 9373, 1924-1925. [CrossRef]

3. Al Mahmud, Z.; Emran, T.B.; Qais, N.; Bachar, S.C.; Sarker, M.; Uddin, M.M.N. Evaluation of analgesic, anti-inflammatory, thrombolytic and hepatoprotective activities of roots of Premna esculenta (Roxb). J. Basic Clin. Physiol. Pharm. 2016, $27,63-70$. [CrossRef]

4. Aziz, M.A.I.; Barua, N.; Tareq, A.M.; Alam, N.; Prova, R.J.; Mamun, M.N.; Sayeed, M.A.; Chowdhury, M.A.U.; Emran, T.B. Possible neuropharmacological effects of Adenia trilobata (Roxb.) in the Swiss Albino mice model. Future J. Pharm. Sci. 2020, 6, 1-8.

5. Jyoti, M.A.; Barua, N.; Hossain, M.S.; Hoque, M.; Bristy, T.A.; Mahmud, S.; Kamruzzaman; Adnan, M.; Chy, M.N.U.; Paul, A.; et al. Unravelling the biological activities of the Byttneria pilosa leaves using experimental and computational approaches. Molecules 2020, 25, 4737. [CrossRef] [PubMed]

6. Rahaman, M.M.; Rakib, A.; Mitra, S.; Tareq, A.T.; Emran, T.B.; Ud-Daula, S.A.F.M.; Amin, M.N.; Simal-Gandara, J. The Genus Curcuma and Inflammation: Overview of the Pharmacological Perspectives. Plants 2021, 10, 63. [CrossRef] [PubMed]

7. Banu, N.; Alam, N.; Islam, M.N.; Islam, S.; Sakib, S.A.; Hanif, N.B.; Chowdhury, M.R.; Tareq, A.M.; Chowdhury, K.H.; Jahan, S.; et al. Insightful Valorization on Biological Activities of Pani Heloch Leaves through Experimental and Computer-Aided Mechanisms. Molecules 2020, 25, 5153. [CrossRef] [PubMed]

8. Saxena, G.; McCutcheon, A.; Farmer, S.; Towers, G.; Hancock, R. Antimicrobial constituents of Rhus glabra. J. Ethnopharmacol. 1994, 42, 95-99. [CrossRef]

9. Calixto, J.B.; Scheidt, C.; Otuki, M.; Santos, A.R. Biological activity of plant extracts: Novel analgesic drugs. Expert Opin. Emerg. Drugs 2001, 6, 261-279. [CrossRef]

10. Akter, S.; Shah, M.; Tareq, A.M.; Nasrin, M.S.; Rahman, M.A.; Babar, Z.; Haque, M.A.; Royhan, M.J.; Mamun, M.N.; Reza, A.A. Pharmacological effect of methanolic and hydro-alcoholic extract of Coconut endocarp. J. Adv. Biotechnol. Exp. 2020, 3, $171-181$. [CrossRef]

11. Uddin, S.N. Traditional Uses of Ethnomedicinal Plants of the Chittagong Hill Tracts; Bangladesh National Herbarium: Dhaka, Bangladesh, 2006.

12. Ali Reza, A.; Hossain, M.S.; Akhter, S.; Rahman, M.R.; Nasrin, M.S.; Uddin, M.J.; Sadik, G.; Khurshid Alam, A. In vitro antioxidant and cholinesterase inhibitory activities of Elatostema papillosum leaves and correlation with their phytochemical profiles: A study relevant to the treatment of Alzheimer's disease. BMC Complement. Altern. Med. 2018, 18, 123. [CrossRef]

13. Williamson, E.M.; Okpako, D.T.; Evans, F.J. Selection, Preparation and Pharmacological Evaluation of Plant Material; John Wiley \& Sons: Hoboken, NJ, USA, 1996; Volume 1.

14. Tareq, A.M.; Sohel, M.; Uddin, M.; Mahmud, M.H.; Hoque, M.; Reza, A.A.; Nasrin, M.S.; Kader, F.B.; Emran, T.B. Possible neuropharmacological effects of Apis cerana indica beehive in the Swiss Albino mice. JABET 2020, 3, 128-134. 
15. Barua, N.; Aziz, M.A.I.; Tareq, A.M.; Sayeed, M.A.; Alam, N.; ul Alam, N.; Uddin, M.A.; Lyzu, C.; Emran, T.B. In vivo and in vitro evaluation of pharmacological activities of Adenia trilobata (Roxb.). Biochem. Biophys. Rep. 2020, 23, 100772.

16. Brand-Williams, W.; Cuvelier, M.-E.; Berset, C. Use of a free radical method to evaluate antioxidant activity. LWT Food Sci. Technol. 1995, 28, 25-30. [CrossRef]

17. Rakib, A.; Ahmed, S.; Islam, M.A.; Uddin, M.M.N.; Paul, A.; Chy, M.N.U.; Emran, T.B.; Seidel, V. Pharmacological studies on the antinociceptive, anxiolytic and antidepressant activity of Tinospora crispa. Phytother. Res. 2020. [CrossRef] [PubMed]

18. Tiwari, P.; Kumar, B.; Kaur, M.; Kaur, G.; Kaur, H. Phytochemical screening and extraction: A review. Int. Pharm. Sci. 2011, 1, 98-106.

19. Uddin, M.Z.; Emran, T.B.; Dutta, M.; Ullah, S.A.; Rana, S.H.M.S. In vivo antidepressant, analgesic, anti-inflammatory activities, in vitro antioxidant and antibacterial potential of fractionated Elatostema papillosum Wed. extract. Pharma Innov. J. 2019, 8, 241-246.

20. Rahman, M.A.; bin Imran, T.; Islam, S. Antioxidative, antimicrobial and cytotoxic effects of the phenolics of Leea indica leaf extract. Saudi J. Biol. Sci. 2013, 20, 213-225. [CrossRef]

21. Rakib, A.; Ahmed, S.; Islam, M.A.; Haye, A.; Uddin, S.N.; Uddin, M.M.N.; Hossain, M.K.; Paul, A.; Emran, T.B. Antipyretic and hepatoprotective potential of Tinospora crispa and investigation of possible lead compounds through in silico approaches. Food Sci. Nutr. 2020, 8, 547-556. [CrossRef]

22. Rahman, J.; Tareq, A.M.; Hossain, M.; Sakib, S.A.; Islam, M.N.; Ali, M.; Uddin, A.; Hoque, M.; Nasrin, M.; Emran, T.B. Biological Evaluation, DFT Calculations and Molecular Docking Studies on the Antidepressant and Cytotoxicity Activities of Cycas pectinata Buch.-Ham. Compounds. Pharmaceuticals 2020, 13, 232. [CrossRef]

23. Bristy, T.A.; Barua, N.; Montakim Tareq, A.; Sakib, S.A.; Etu, S.T.; Chowdhury, K.H.; Jyoti, M.A.; Aziz, M.; Ibn, A.; Reza, A. Deciphering the pharmacological properties of methanol extract of Psychotria calocarpa leaves by in vivo, in vitro and in silico approaches. Pharmaceuticals 2020, 13, 183. [CrossRef]

24. Dutta, T.; Paul, A.; Majumder, M.; Sultan, R.A.; Emran, T.B. Pharmacological evidence for the use of Cissus assamica as a medicinal plant in the management of pain and pyrexia. Biochem. Biophys. Rep. 2020, 21, 100715. [CrossRef]

25. Jahan, I.; Tona, M.R.; Sharmin, S.; Sayeed, M.A.; Tania, F.Z.; Paul, A.; Chy, M.; Uddin, N.; Rakib, A.; Emran, T.B. GC-MS phytochemical profiling, pharmacological properties, and in silico studies of Chukrasia velutina leaves: A novel source for bioactive agents. Molecules 2020, 25, 3536. [CrossRef]

26. Khan, S.; Nazir, M.; Raiz, N.; Saleem, M.; Zengin, G.; Fazal, G.; Saleem, H.; Mukhtar, M.; Tousif, M.I.; Tareen, R.B. Phytochemical profiling, in vitro biological properties and in silico studies on Caragana ambigua stocks (Fabaceae): A comprehensive approach. Ind. Crops Prod. 2019, 131, 117-124. [CrossRef]

27. Adnan, M.; Chy, N.U.; Mostafa Kamal, A.; Azad, M.O.K.; Paul, A.; Uddin, S.B.; Barlow, J.W.; Faruque, M.O.; Park, C.H.; Cho, D.H. Investigation of the biological activities and characterization of bioactive constituents of Ophiorrhiza rugosa var. prostrata (D. Don) \& Mondal leaves through in vivo, in vitro, and in silico approaches. Molecules 2019, 24, 1367.

28. Ahmed, S.; Rakib, A.; Islam, M.A.; Khanam, B.H.; Faiz, F.B.; Paul, A.; Chy, M.N.U.; Bhuiya, N.M.A.; Uddin, M.M.N.; Ullah, S.A. In vivo and in vitro pharmacological activities of Tacca integrifolia rhizome and investigation of possible lead compounds against breast cancer through in silico approaches. Clin. Phytosci. 2019, 5, 36. [CrossRef]

29. Grosser, T.; Theken, K.N.; FitzGerald, G.A. Cyclooxygenase inhibition: Pain, inflammation, and the cardiovascular system. Clin. Pharm. 2017, 102, 611-622. [CrossRef] [PubMed]

30. Hasanat, A.; Chowdhury, T.A.; Kabir, M.S.H.; Chowdhury, M.S.; Chy, M.; Uddin, N.; Barua, J.; Chakrabarty, N.; Paul, A. Antinociceptive Activity of Macaranga denticulata Muell. Arg. (Family: Euphorbiaceae): In Vivo and In Silico Studies. Medicines 2017, 4, 88. [CrossRef] [PubMed]

31. Tareq, A.M.; Farhad, S.; Uddin, A.N.; Hoque, M.; Nasrin, M.S.; Uddin, M.M.R.; Hasan, M.; Sultana, A.; Munira, M.S.; Lyzu, C. Chemical profiles, pharmacological properties, and in silico studies provide new insights on Cycas pectinata. Heliyon 2020, 6 , e04061. [CrossRef] [PubMed]

32. Krisnamurti, G.; Fatchiyah, F. Interaction of acetaminophen and caffeine towards cyclooxygenase-2 (COX-2) in inhibition of prostaglandin (PGH 2) synthesis. JPhCS 2019, 1146, 012004.

33. Baeuerle, P.A.; Baichwal, V.R. NF-kB as a frequent target for immunosuppressive and anti-inflammatory molecules. Adv. Immunol. 1997, 65, 111-138. [PubMed]

34. Xu, L.; Liu, Y.; Sun, Y.; Li, H.; Mi, W.; Jiang, Y. Analgesic effects of TLR4/NF-KB signaling pathway inhibition on chronic neuropathic pain in rats following chronic constriction injury of the sciatic nerve. Biomed. Pharm. 2018, 107, 526-533. [CrossRef] [PubMed]

35. Machado, M.S.S.; Silva, H.B.F.; Rios, R.; de Oliveira, A.P.; Carneiro, N.V.Q.; Costa, R.S.; Alves, W.S.; Souza, F.-L.M.; da Silva Velozo, E.; de Souza, S.A. The anti-allergic activity of Cymbopogon citratus is mediated via inhibition of nuclear factor kappa B (NF-KB) activation. BMC Complement. Altern. Med. 2015, 15, 168.

36. Joseph, A.; Thuy, T.T.T.; Thanh, L.T.; Okada, M. Antidepressive and anxiolytic effects of ostruthin, a TREK-1 channel activator. PLoS ONE 2018, 13, e0201092. [CrossRef]

37. Kubacka, M.; Mogilski, S.; Bednarski, M.; Nowiński, L.; Dudek, M.; Żmudzka, E.; Siwek, A.; Waszkielewicz, A.M.; Marona, H.; Satała, G. Antidepressant-like activity of aroxyalkyl derivatives of 2-methoxyphenylpiperazine and evidence for the involvement of serotonin receptor subtypes in their mechanism of action. Pharm. Biochem. Behav. 2016, 141, 28-41. [CrossRef] 
38. Adnan, M.; Chy, M.; Uddin, N.; Kama, A.; Azad, M.; Kalam, O.; Chowdhury, K.A.A.; Kabir, M.S.H.; Gupta, S.D.; Chowdhury, M. Comparative Study of Piper sylvaticum Roxb. Leaves and Stems for Anxiolytic and Antioxidant Properties Through in vivo, in vitro, and in silico Approaches. Biomedicines 2020, 8, 68. [CrossRef]

39. Bharathi, R.; Santhi, N. 4-(3-(2-amino-3, 5-dibromophenyl)-1-(4-substitutedbenzoyl)-4, 5-dihydro-1H-pyrazol-5-yl) benzonitrile as a novel anti-Inflammatory scaffold: Synthesis, biological evaluation and docking studies. World Sci. News 2019, 126, 148-162.

40. Duffy, F.J.; Devocelle, M.; Shields, D.C. Computational approaches to developing short cyclic peptide modulators of proteinprotein interactions. In Computational Peptidology; Springer: New York, NY, USA, 2015; pp. 241-271.

41. Lipinski, C.A.; Lombardo, F.; Dominy, B.W.; Feeney, P.J. Experimental and computational approaches to estimate solubility and permeability in drug discovery and development settings. Adv. Drug Deliv. Rev. 1997, 23, 3-25. [CrossRef]

42. Daina, A.; Michielin, O.; Zoete, V. iLOGP: A simple, robust, and efficient description of n-octanol/water partition coefficient for drug design using the GB/SA approach. J. Chem. Inf. Model. 2014, 54, 3284-3301. [CrossRef]

43. Berman, H.; Battistuz, T.; Bhat, T.; Bluhm, W.; Bourne, P.; Burkhardt, K.; Feng, Z.; Gilliland, G.; Iype, L.; Jain, S. The protein data bank. Acta Crystallogr. D Biol. Cryst. 2002, 58, 899-907. [CrossRef]

44. Lenaeus, M.J.; Burdette, D.; Wagner, T.; Focia, P.J.; Gross, A. Structures of KcsA in complex with symmetrical quaternary ammonium compounds reveal a hydrophobic binding site. Biochemistry 2014, 53, 5365-5373. [CrossRef] [PubMed]

45. Coleman, J.A.; Green, E.M.; Gouaux, E. X-ray structures and mechanism of the human serotonin transporter. Nature 2016, 532, 334-339. [CrossRef]

46. Zheng, C.; Yin, Q.; Wu, H. Structural studies of NF-кB signaling. Cell Res 2011, 21, 183-195. [CrossRef]

47. Harman, C.A.; Turman, M.V.; Kozak, K.R.; Marnett, L.J.; Smith, W.L.; Garavito, R.M. 2007. Structural basis of enantioselective inhibition of cyclooxygenase-1 by S-alpha-substituted indomethacin ethanolamides. J. Biol. Chem. 2007, 282, 28096-28105. [CrossRef] [PubMed]

48. Kurumbail, R.G.; Stevens, A.M.; Gierse, J.K.; McDonald, J.J.; Stegeman, R.A.; Pak, J.Y.; Stallings, W.C. Structural basis for selective inhibition of cyclooxygenase-2 by anti-inflammatory agents. Nature 1996, 384, 644-648. [CrossRef]

49. Sastry, G.M.; Adzhigirey, M.; Day, T.; Annabhimoju, R.; Sherman, W. Protein and ligand preparation: Parameters, protocols, and influence on virtual screening enrichments. J. Comput. Aided Mol. Des. 2013, 27, 221-234. [CrossRef] [PubMed]

50. Friesner, R.A.; Banks, J.L.; Murphy, R.B.; Halgren, T.A.; Klicic, J.J.; Mainz, D.T.; Repasky, M.P.; Knoll, E.H.; Shelley, M.; Perry, J.K. Glide: A new approach for rapid, accurate docking and scoring. 1. Method and assessment of docking accuracy. J. Med. Chem. 2004, 47, 1739-1749. [CrossRef]

51. Chy, M.N.U.; Adnan, M.; Rauniyar, A.K.; Amin, M.M.; Majumder, M.; Islam, M.S.; Afrin, S.; Farhana, K.; Nesa, F.; Sany, M.A. Evaluation of anti-nociceptive and anti-inflammatory activities of Piper sylvaticum (Roxb.) stem by experimental and computational approaches. Orient. Pharm. Exp. Med. 2019, 1-15. [CrossRef]

52. Chen, F.; Liu, H.; Sun, H.; Pan, P.; Li, Y.; Li, D.; Hou, T. Assessing the performance of the MM/PBSA and MM/GBSA methods. 6. Capability to predict protein-protein binding free energies and re-rank binding poses generated by protein-protein docking. Phys. Chem. Chem. Phys. 2016, 18, 22129-22139. [CrossRef]

53. Krieger, E. Yet another Scientific Artificial Reality Application (YASARA). 2004. Available online: http://www.yasara.org/ (accessed on 4 February 2021).

54. Case, D.A.; Cerutti, D.S.; Cheatham, T.E.; Darden, T.A.; Duke, R.E.; Giese, T.J.; Gohlke, H.; Goetz, A.W.; Greene, D.; Homeyer, N.; et al. The Amber biomolecular simulation programs. J. Comput. Chem. 2005, 26, 1668-1688. [CrossRef]

55. Krieger, E.; Nielsen, J.E.; Spronk, C.A.E.M.; Vriend, G. Fast empirical p K a prediction by Ewald summation. J. Mol. Graph. Model. 2006, 25, 481-486. [CrossRef] [PubMed]

56. Krieger, E.; Vriend, G. New ways to boost molecular dynamics simulations. J. Comput. Chem. 2015, 36, 996-1007. [CrossRef] [PubMed]

57. Bappy, S.S.; Sultana, S.; Adhikari, J.; Mahmud, S.; Khan, M.A.; Kibria, K.M.K.; Rahman, M.M.; Shibly, A.Z. Extensive immunoinformatics study for the prediction of novel peptide-based epitope vaccine with docking confirmation against envelope protein of Chikungunya virus: A computational biology approach. J. Biomol. Struct. Dyn. 2020, 24, 1-16. [CrossRef] [PubMed]

58. Swargiary, A.; Mahmud, S.; Saleh, M.A. Screening of phytochemicals as potent inhibitor of 3-chymotrypsin and papain-like proteases of SARS-CoV2: An in silico approach to combat COVID-19. J. Biomol. Struct. Dyn. 2020, 22, 1-15. [CrossRef] [PubMed]

59. Khan, M.A.; Mahmud, S.; Alam, A.S.M.R.U.; Rahman, M.E.; Ahmed, F.; Rahmatullah, M. Comparative molecular investigation of the potential inhibitors against SARS-CoV-2 main protease: A molecular docking study. J. Biomol. Struct. Dyn. 2020, $22,1-7$. [CrossRef] [PubMed] 